\title{
Implementation of bi-directional searching Chemical Reaction Optimization (CRO) algorithm towards achieving cutting tool indexing time minimization in Automatic Tool Changer(ATC)
}

DOI : 10.36909/jer.10845

Karthikeyan Arthanary*, Karthikeyan Ayyavoo**, K Venkatesh Raja*** T Pridhar ****

*Department of Mechanical Engineering, Excel Engineering College, Tamil Nadu, India

**Department of Mechanical Engineering, Coimbatore Institute of Technology, Coimbatore, Tamil Nadu, India

***Department of Mechanical Engineering, Sona College of Technology, Salem, Tamil Nadu, India.

**** Department of Mechanical Engineering, Sri Krishna college of technology, Coimbatore, Tamil Nadu, India

\begin{abstract}
Determining the optimum cutting tool positions in a tool magazine is a challenging task which involves a huge searching space. Reduction of manufacturing time even by nanoseconds will highly be beneficial for all process industries. The prime focus of this research work is to reduce the total turret or tool indexing time in Automatic Tool Changer (ATC) which in turn curtails the idle non-cutting time of the bi-directional turret or tool magazine in a CNC machine. This variant of optimization problem falls under the category of non-deterministic hard polynomial (NP-hard) problem. Chemical Reaction Optimization (CRO) algorithm is proposed to determine the near optimal/global optimal solution with lesser computational cost. Five benchmark case studies are considered in this work to assess the robustness of the proposed
\end{abstract}


algorithm. From the results, it is evident that the proposed algorithm yields solutions which matches or exceeds with the solution quality.

Keywords: Turret indexing time, Chemical reaction algorithm, Automatic tool changer, tool indexing optimization

\section{Introduction}

Tool indexing is a process of allocation of cutting tools to different slots within a tool magazine of a CNC machine. This process should be treated as a vital one as it has a significant impact on the minimization of tool change time in any automated machining process industry. The turret magazine or automatic tool changer (ATC) is capable of holding multiple tools in different slots/pockets to promote the automatic implementation of the sequence of the operations. In the present industry scenario, most of the $\mathrm{CNC}$ turning and $\mathrm{CNC}$ milling machining centre are equipped with high-speed turrets which reduce the indexing time of the Automatic tool changer still there is need for a proper effective tool allotment policy to reduce the non-cutting time of the machining process an increase production rate.

Tool indexing is a process of allocation of cutting tools to different slots within a tool magazine of a CNC machine. This process should be treated as a vital one as it has a significant impact over the minimization of tool change time in any automated machining process industry. The turret magazine or automatic tool changer (ATC) is capable of holding multiple tools in different slots/pockets to promote the automatic implementation of the operations sequence. Whenever the tool is required during the machining process, it has to be readily available in the ATC or turret. The indexing position of the tool decides the idle time of the machine, by proper positioning of the tool as per the machining sequence order which 
reduces the turret or ATC rotations from one position of the tool to the next position. In the current industry scenario, most of the CNC turning and CNC milling machining centre was equipped with high speed turrets which reduce the indexing time of the Automatic Tool Changer (ATC) still there is a need of a proper effective tool allotment policy in order to reduce the noncutting time of the machining process an increase production rate.

An Initial attempt of tool switching time minimization was proposed by (Dereli et al., 1998). This type of allocation policy is very essential if the machine is not loaded with a high-speed turret system. Dereli\&Filiz (2000) proposed a Genetic Algorithm based optimization algorithm for tool indexing position in automatic tool changer along with operation sequencing problem. They developed a separate optimization package for solving simple tool indexing problem with few tools. Baykasogluy\&Dereliy (2004) used Simulated Annealing Algorithm (SAA) to search the global solutions for optimizing the tool indexing positions. Four major case studies were considered to check the performance of the proposed algorithm. The duplication of cutting tools in the ATC improves the indexing time. One similar work is presented by Wilson (1987), where a different objective function is used and tool duplication is not considered. As stated by Gray, S \& Stecke (1993), an important, unanswered research problem involves determining the optimal number of copies of each tool type to load into a magazine. Krishna A.G. \& Mallikarjuna Rao, M. (2005) presented an ant colony - based optimization algorithm to allocate the tool in ATC. The global searching technique was incorporated in the algorithm which quickly identifies the optimal solutions. The main objective of the research is to minimize the tool indexing time.

Velmurugan \& Victor Raj (2013) used a particle swarm optimization algorithm for the tool indexing problem with 14 tools and 28 slots. Baykasoglu\&Ozsoydan (2015) developed the 
shortest path algorithm for optimizing the tool indexing position by considering tool duplications. Many case studies were considered from small to medium and large size problems to test the performance of the proposed algorithm. CNC machine tool indexing problem instances were solved by genetic, tabu and neighbourhood searching techniques (Ghosh 2016a, b, c, d, e, f). Atta et al. (2018) proposed Harmony Search (HS) based algorithm to improve the tool indexing position in the automatic tool magazine. However, to the authors' knowledge, this problem has not been attempted by the chemical reaction optimization algorithm in the literature. In this research, a chemical reaction optimization algorithm is developed to calculate the optimal possible index position of the cutting tool in a magazine.

\section{Problem Definition}

Nowadays most machine tool manufacture produce CNC machines with fast tool indexing capacity to reduce the non-machining time. Still, there is a need for an effective tool arrangement policy to reduce the total indexing time. The tool indexing time of the magazine or turret depends upon spindle rotational speed. A typical ATC indexing of milling machine is usually higher than the turret due to the heavier cutter in the ATC system. In CNC machine the tool indexing system or turret moves in unidirectional or bidirectional capacity. Due to drawbacks of unidirectional system, bidirectional is mostly used in industry. A Bidirectional system reduces the total indexing time as compared to a unidirectional system. If ATC rotates in both directions, then the selection of a tool which is near to the previous tool which reduces the indexing time /rotation. A typical Automatic Tool Index (ATC) is shown in Figure 1. Further, the classification of tool indexing position is portrayed in the picture for reference. 


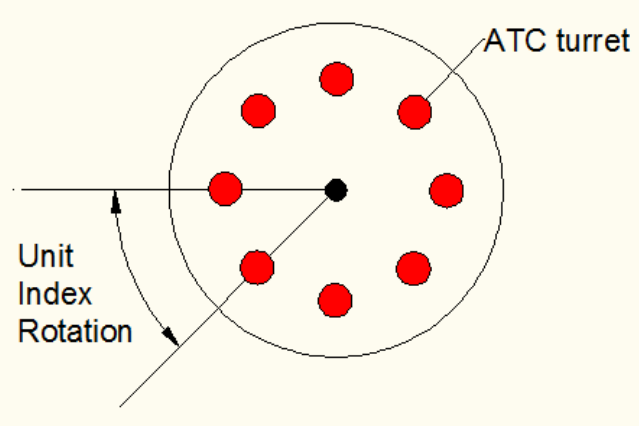

Figure 1. Automatic Tool Index

In this research work, case I and case II without tool duplication is considered and the objective function is mapped to minimize the total indexing time. Case I and II are the most frequently occurred situation in many industries where the secondary ATC setup is not required which reduces the total machining time. Case III is a complicated situation wherein a greater number of duplications of the same tools is permitted which significantly reduces the total indexing time.

However, modeling of duplicate tools increase the complexity of the problem to a higher extent. Hence future work of this research may be extended to tool duplication study which might further reduce the indexing time. The final one (Case IV) is the most complicated situation as the number of tools are more than turret or ATC. In the case more than one arrangement of tool setup may be needed. The details of all cases are shown below Figure 2(a-d) 


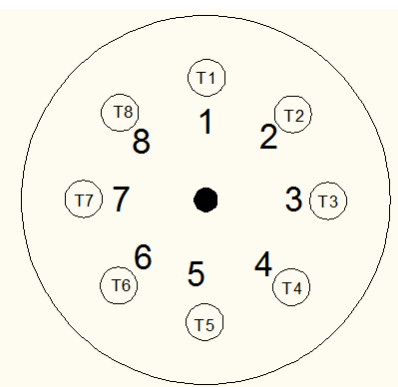

a) Case I - Number of tools $=$ Number of Index Turret

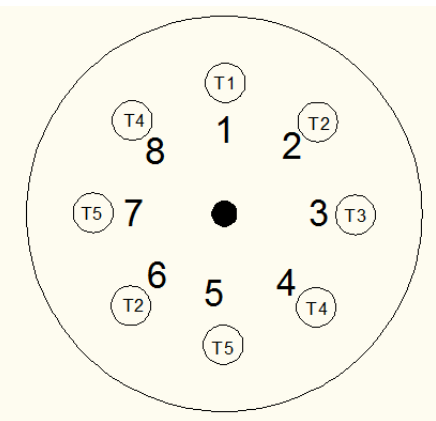

a) Case III - Number of tools $<$ Number of Index Turret

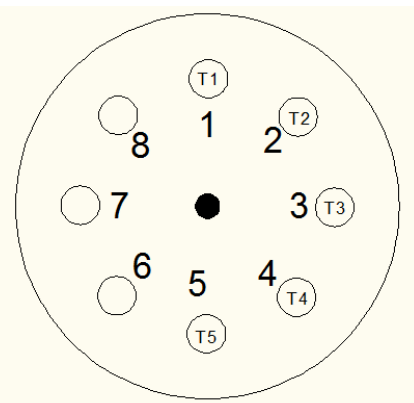

b) Case II - Number of tools < Number of Index Turret (without Tool duplication)

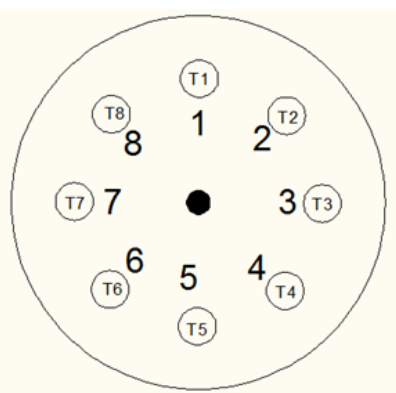

Set 1

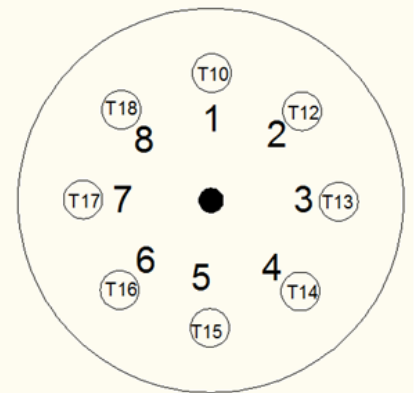

Set 2 b) Case IV - Number of tools > Number of Index Turret

Figure 2. Schema of tool indexing problem.

\section{Methodology}

\subsection{Inputs for Tool indexing problem}

For solving tool indexing problem following inputs are needed

a. Number of machining operations

b. Number of tools used 
c. A list of tools assigned to each machining operation

d. Number of index position in tool magazine/ turret

e. Indexing time between each tool movements

\subsection{Assumptions}

i. Weight of cutting tool neglected

ii. Speed of indexing machine is assumed uniform

iii. After allocation of tool, interchanging of tools not allowed.

iv. Tool is unloaded from position 1 and it again loaded to same position 1

v. Work piece material properties not considered.

vi. Weight of tool is negligible in ATC.

\subsection{Objective function}

The objective function is to minimize the total indexing time of turret magazine or ATC by optimal positioning of tools. The tool indexing time is estimated by adding the summation of rotational indexing time of individual tools in the ATC. The shortest rotational time of a particular tool is referred from the current index position to the machining operation order either in clock-wise or counter clock wise direction. Equation (1) is used to calculate the total indexing time without any tool duplication. (Dereli et al. 1999)

Tool indexing time estimation

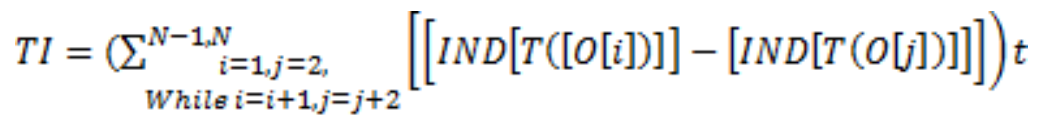

Where

O- Machining operations, T- Tool, N- Number of operations, t- Indexing time of each pair ,IND- represents the tool position in magazine 
The term IND $[\mathrm{T}(\mathrm{O}[\mathrm{i}])]$ is represents the tool used for $\mathrm{i}^{\text {th }}$ machining operation; IND represents the position of the tool in the turret magazine. The summation of the rotational count of each pair of tool position is calculated by the first term of Equation (3.6), which multiplied by the indexing time ' $t$ ' of each unit rotation.

\subsection{Procedure for calculating tool indexing time}

Step1 : Enter the inputs for tool indexing problem.

Number of operations $\quad: 10$

Tools required $\quad: 6$

Capacity of Turret IATC : 6

Indexing Time $\quad: 2 \mathrm{sec}$

The details of operations and corresponding tools are presented in Table 1.

Table 1. Details of operations and tools required

\begin{tabular}{ccccccccccc}
\hline Operations No. & $\mathbf{1}$ & $\mathbf{2}$ & $\mathbf{3}$ & $\mathbf{4}$ & $\mathbf{5}$ & $\mathbf{6}$ & $\mathbf{7}$ & $\mathbf{8}$ & $\mathbf{9}$ & $\mathbf{1 0}$ \\
\hline Optimum Process Plan & 4 & 5 & 6 & 2 & 1 & 3 & 7 & 9 & 10 & 8 \\
\hline Tools Required & 3 & 2 & 1 & 5 & 1 & 3 & 1 & 6 & 4 & 3 \\
\hline
\end{tabular}

Step 2: Now the tools are randomly positioned in turret or index

Example: The arrangement of six tools in a ATC turret is randomly generated as shown below

$\begin{array}{lllllll}\text { Turret Position : } & 1 & 2 & 3 & 4 & 5 & 6 \\ \text { Generated Tool id : } & 3 & 1 & 6 & 5 & 2 & 4\end{array}$




\section{Step3 : Indexing time estimation}

The indexing time is calculated based on tool position in the ATC which is shown in Table 2.

Table 2 Tool indexing time estimation

\begin{tabular}{|l|l|l|l|l|l|l|l|l|l|l|}
\hline Operation No & 1 & 2 & 3 & 4 & 5 & 6 & 7 & 8 & 9 & 10 \\
\hline Tools Required & 3 & 2 & 1 & 5 & 1 & 3 & 1 & 6 & 4 & 3 \\
\hline $\begin{array}{l}\text { Generated } \\
\text { Tool id }\end{array}$ & 3 & 1 & 6 & 5 & 2 & 4 & & & & \\
\hline Tool movement & $3-3$ & $3-2$ & $2-1$ & $1-5$ & $5-1$ & $1-3$ & $3-1$ & $1-6$ & $6-4$ & $4-3$ \\
\hline Index Direction & $\mathrm{NR}$ & $\mathrm{CW}$ & $\mathrm{CCW}$ & $\mathrm{CW}$ & $\mathrm{CCW}$ & $\mathrm{CCW}$ & $\mathrm{CW}$ & $\mathrm{CW}$ & $\mathrm{CCW}$ & $\mathrm{CW}$ \\
\hline Index time & 0 & 8 & 6 & 4 & 4 & 2 & 2 & 2 & 6 & 2 \\
\hline Total index time & 0 & 8 & 14 & 18 & 22 & 24 & 26 & 28 & 34 & 36 \\
\hline
\end{tabular}

Where NR- No Rotation, CW - clock wise rotation, CCW- counter clock wise rotation

The respective tools were searched in turret either clock wise or counter clock wise direction as per the requirements of machining operation. This random number of tool position is optimized with help of optimization algorithm due to huge computational requirements, for example 10 tools needed $10 !=36,28,800$ combinations of sequences, further complexity increases when number of tools are greater than turret or ATC capacity. In many situations optimum solutions were trapped in local minimum. To overcome this difficulty, the new novel heuristic Chemical Reaction Optimization (CRO) algorithm were developed, which is capable searching the 
solutions in a global space. The same indexing time calculation procedure adopted in Case I, case II, But in case III, empty tools included in order to search shortest number of rotations.

\section{Chemical reaction algorithm}

It is a meta heuristic algorithm which inspires the natural chemical reaction process. The merits of the CRO algorithm is having the features of hill climbing except from local solutions and its characteristics similar to the simulated annealing algorithm.

The major stages followed in CRO algorithm is as follows

Stage I: One molecule to one molecule process(Deformation)

Stage II :One molecule to two molecules process( Decomposition)

Stage III: Two molecules to one molecule process(Combination)

Stage IV: Two molecules to two molecules process(collaboration)

In this algorithm tool indexing sequence are considered as molecule, due to simplicity and ease implementation of this algorithm, nowadays it is applicable to solve many engineering problems. The detailed step of algorithm is shown below

1. Get the Inputs (Number of operation, Number of Tools, Number of Turret Index Position, Tools specified for each tools)

2. Initialize number of global and local iterations (sub stages)of the algorithm.

3. Generate the molecules randomly (Tool position sequence) in a global search space and calculate the index time as per tool calculation procedure. 
Table 3 Indexing time calculation

\begin{tabular}{|c|c|c|c|c|c|c|c|}
\hline \multirow[t]{2}{*}{ Seq.No } & \multicolumn{6}{|c|}{ Turret or Tool index position } & \multirow{2}{*}{$\begin{array}{l}\text { Index Time } \\
(\mathrm{Sec})\end{array}$} \\
\hline & 1 & 2 & 3 & 4 & 5 & 6 & \\
\hline & \multicolumn{6}{|c|}{ Generated Tool Position } & \\
\hline 1 & 3 & 4 & 5 & 2 & 1 & 6 & 49.5 \\
\hline 2 & 6 & 2 & 3 & 5 & 4 & 1 & 37.5 \\
\hline 3 & 4 & 6 & 5 & 3 & 1 & 2 & 55.5 \\
\hline 4 & 2 & 5 & 3 & 4 & 6 & 1 & 87.5 \\
\hline 5 & 1 & 6 & 5 & 4 & 3 & 2 & 67.00 \\
\hline 6 & 5 & 4 & 6 & 1 & 2 & 3 & 51.5 \\
\hline 7 & 6 & 4 & 5 & 2 & 1 & 3 & 49.5 \\
\hline $\mathrm{N}$ & . & . & . & . & . & . & . \\
\hline
\end{tabular}

At the initial stage 25 to 50 sequences were randomly generated and corresponding Total index time calculated in order to search the solutions globally.

3) Select the high fitness solutions i.e. low indexing time sequences to next iteration

4) Apply the deformation (1 to 1 action): pick random sequence from above initial stage and swap the variables randomly

$\begin{array}{ccc}\text { Input } & \text { Swap } & \text { Output } \\ & \text { location } & \\ 34 \mathbf{5} 162 & 3,5 & 34 \mathbf{6} 1 \mathbf{5} 2 \\ \mathbf{2} 16345 & 1,5 & \mathbf{4 1 6 3 2 5}\end{array}$




\section{$631524 \quad 3,6 \quad 634521$}

Again, the high fitness solution shortlisted to next stage of the algorithm

5) Decomposition (one to two actions)

In this stage one sequence randomly picked and separated in to two sequences, by keeping left or right half constantly and rest randomly swapped.

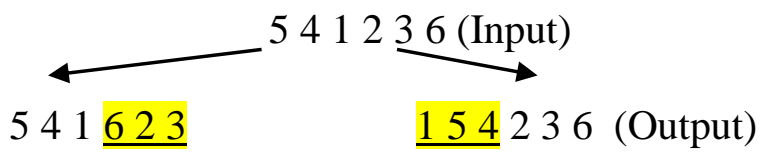

Again calculate the fitness and take best sequences to stage III process.

6) Combination ( 2 to 1 )

In these stage two sequences were randomly selected and combine into one sequence by positioning alternate term from two sequences

\section{$623154 \quad 145623$ (Input)}

612435 (Output)

Now solutions converge to near optimal stage, further this algorithm continues to next stage till improved solutions occurs.

7) Collaboration ( 2 to 2 )

This is the final stage of CRO algorithm, the high fitness sequences were randomly picked and left or right half sequences were randomly swapped by keeping one half sequence as constant. 


\section{$345 \underline{612}$}

\section{$243 \underline{126}$ (Output)}

After completing the final stage, the optimal solutions were stored for all stages of the algorithm. This process extended till reach the prescribed number of iterations (50 to $500)$.

4. Validation of the proposed algorithm with Industrial Case study

The performance of proposed algorithm validated with five industrial case studies from standard literature. The algorithm was coded in Turbo $\mathrm{C}++$ and tested in Pentium core 2 duo processor with 2 GB RAM capacity.

\subsection{Case study 1 :}

Prismatic part with 16 operations and it requires 9 tools were used which is refereed from Dereli(1999). The detailed operations for each machining feature were shown in Figure 3 and Table 4. The total turret index position is equal to number of tools. The indexing time between each tool movement is $0.69 \mathrm{sec}$. 


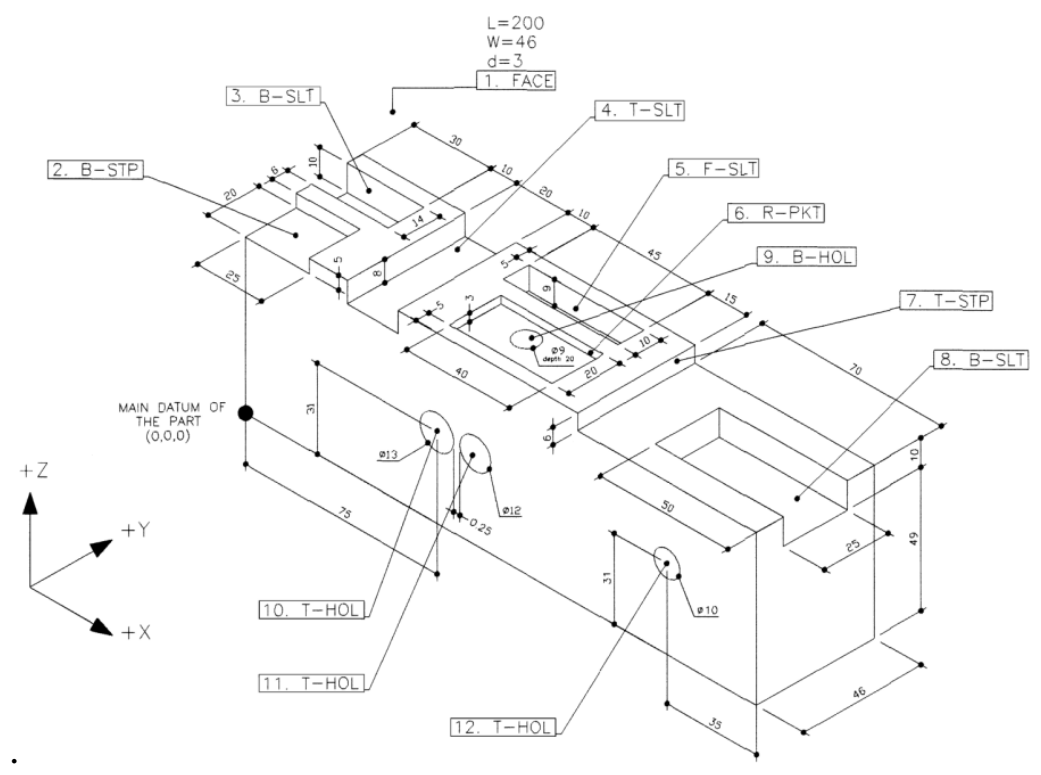

Figure 3 Machining Feature with 16 operations

Table 4. Machining Operations and corresponding Tools

\begin{tabular}{|c|c|}
\hline Operation No & O1 O2 O3 O4 O5 O6 O7 O8 O9 O10 O11 O12 O13 O14 O15 O16 \\
\hline Tools Assigned & 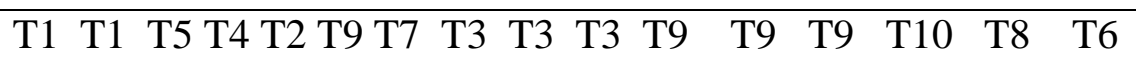 \\
\hline
\end{tabular}

The result obtained by this algorithm is $8.9 \mathrm{sec}$ which is similar in Dereli et.al( 2000). The convergence of results shown following Figure 4. The solutions convergence rate is much faster than genetic and simulated algorithm proposed by Dereli and Filiz (2000).This results were better than experienced workers prediction. Even small micro seconds saves huge production rate when volume increased. 


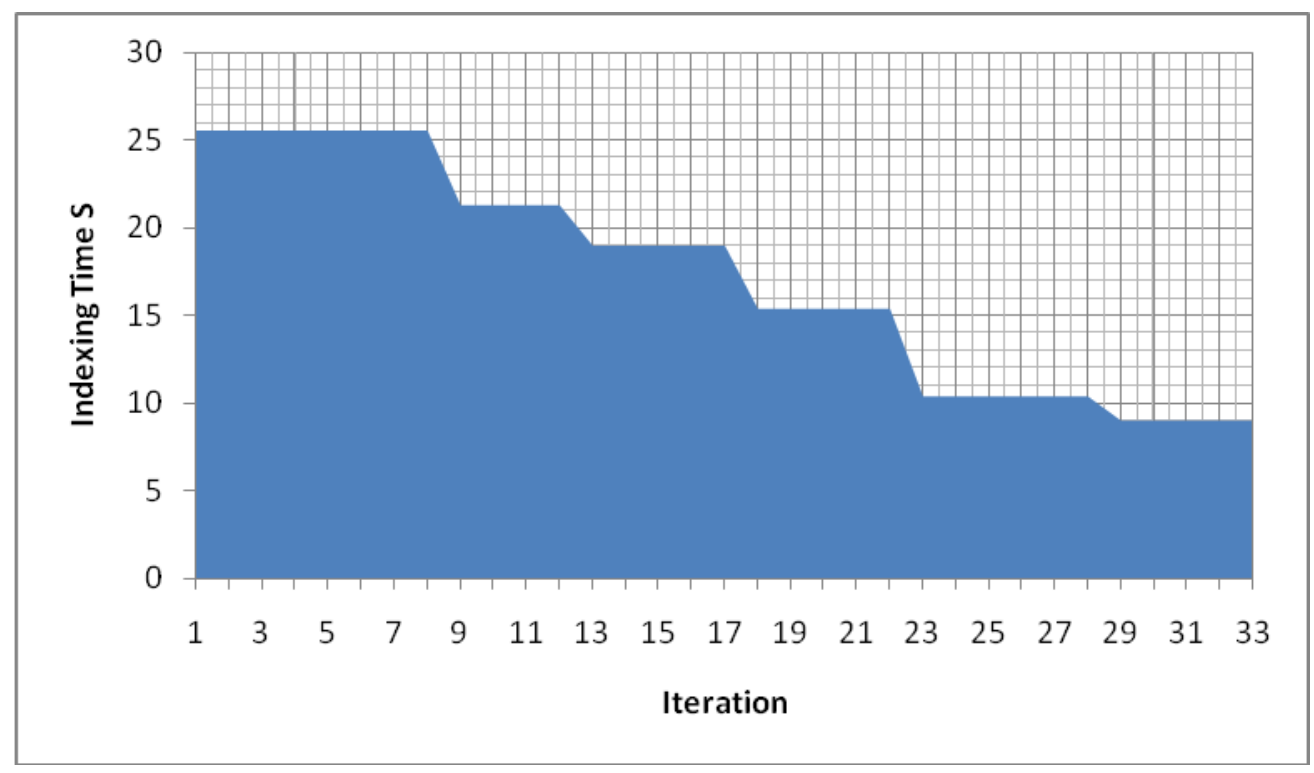

Figure 4. Convergences of solutions

\subsection{Case Study 2 :}

In this case, 17 machining operations with 9 tools were referred from Krishna. A.G, Rao . K. M (2006). The index time between each tool position is $0.69 \mathrm{sec}$. The number of tools are equal to number of turret position. The details of machining operations and tools required is shown in Table 5.

Table 5. Machining Operations and corresponding Tools

\begin{tabular}{|c|c|}
\hline Operation No & $\mathrm{O} 1 \mathrm{O} 2 \mathrm{O} 3 \mathrm{O} 4 \mathrm{O} 5 \mathrm{O} 6 \mathrm{O} 7 \mathrm{O} 8 \mathrm{O} 9 \mathrm{O} 10 \mathrm{O} 11 \mathrm{O} 12 \mathrm{O} 13 \mathrm{O} 14 \mathrm{O} 15 \mathrm{O} 16 \mathrm{O} 17$ \\
\hline Tools Assigned & 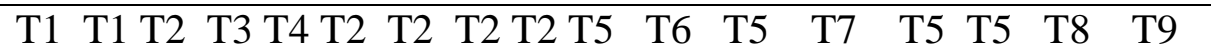 \\
\hline
\end{tabular}

The obtained optimum result is presented in Table 10. which shows similar results as proposed in scatter search algorithm and solutions convergence rate of the proposed algorithm is much faster. 


\subsection{Case study 3 :}

In this case 27 operations and 14 tools were used which is referred from Adil Baykasoglu a \& Türkay Dereli(2007). The number of tools equal to Number of Turret positions. The index time is $0.69 \mathrm{sec}$ which is shown in Table 6.

Table 6. Machining Operations and corresponding Tools

\begin{tabular}{|c|c|}
\hline operation No & $\mathrm{O} 1 \mathrm{O} 2 \mathrm{O}^{2} \mathrm{O} 4 \mathrm{O} 5 \mathrm{O} 6 \mathrm{O} 7 \mathrm{O} 8 \mathrm{O} 9 \mathrm{O} 10 \mathrm{O} 11 \mathrm{O} 12 \mathrm{O} 13 \mathrm{O} 14 \mathrm{O} 15 \mathrm{O} 16 \mathrm{O} 17$ \\
\hline Tools Assigned & 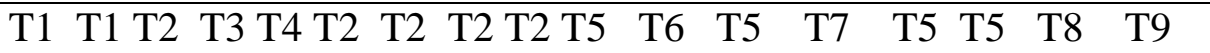 \\
\hline Operation No & O18 O19 O20 O21 O22 O23 O24 O25 O26 O27 \\
\hline Tools Assigned & $\begin{array}{lllllllll}\text { T5 } & \text { T10 } & \text { T5 } & \text { T11 T5 } & \text { T12 } & \text { T5 } & \text { T13 } & \text { T5 } & \text { T14 }\end{array}$ \\
\hline
\end{tabular}

The convergence of optimum solutions at various stages of chemical reaction optimization algorithm is shown in Table 7. The indexing time is dropped to minimum in each stage of the algorithm.

Table 7. Chemical reaction optimization algorithm objective function converges.

\begin{tabular}{|l|l|l|}
\hline Stages & Tool Sequences & $\begin{array}{l}\text { Total index } \\
\text { Time }(\mathrm{Sec})\end{array}$ \\
\hline Initial Generation & 2713581114912631041 & 46.92 \\
\cline { 2 - 4 } & 3214971012865111314 & 45.54 \\
\cline { 2 - 4 } & 8436129710513142111 & 45.54 \\
\hline Deformation & 1434112928135116710 & 44.16 \\
\cline { 2 - 4 } & 4321314105961112871 & 42.78 \\
\cline { 2 - 4 } & 8142143117135610912 & 38.64 \\
\hline Decomposition & 2181214106571311943 & 38.64 \\
\hline
\end{tabular}




\begin{tabular}{|c|c|c|}
\hline & 3189101161251374142 & 38.64 \\
\hline & 2191310512611714843 & 38.64 \\
\hline & 1410712561311938421 & 37.26 \\
\hline Combination & 8914101113561272431 & 35.88 \\
\hline & 1413241012651371189 & 35.88 \\
\hline & 1342146121051113879 & 35.88 \\
\hline & 1432101113751268149 & 35.88 \\
\hline & 1414101367512119823 & 35.88 \\
\hline & 1413241171051312689 & 35.88 \\
\hline Collaboration & 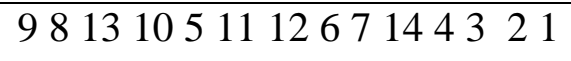 & 35.19 \\
\hline & 1711651013121498432 & 34.50 \\
\hline & 1713651211101498432 & 34.50 \\
\hline & 1981213651110714234 & 34.50 \\
\hline
\end{tabular}

The obtained results is $34.50 \mathrm{sec}$ which is similar in simulated annealing algorithm proposed by Adil Baykasoglu a \& Türkay Dereli(2007). The solutions convergence rate is much faster than literature algorithm which is shown in Figure 5. 


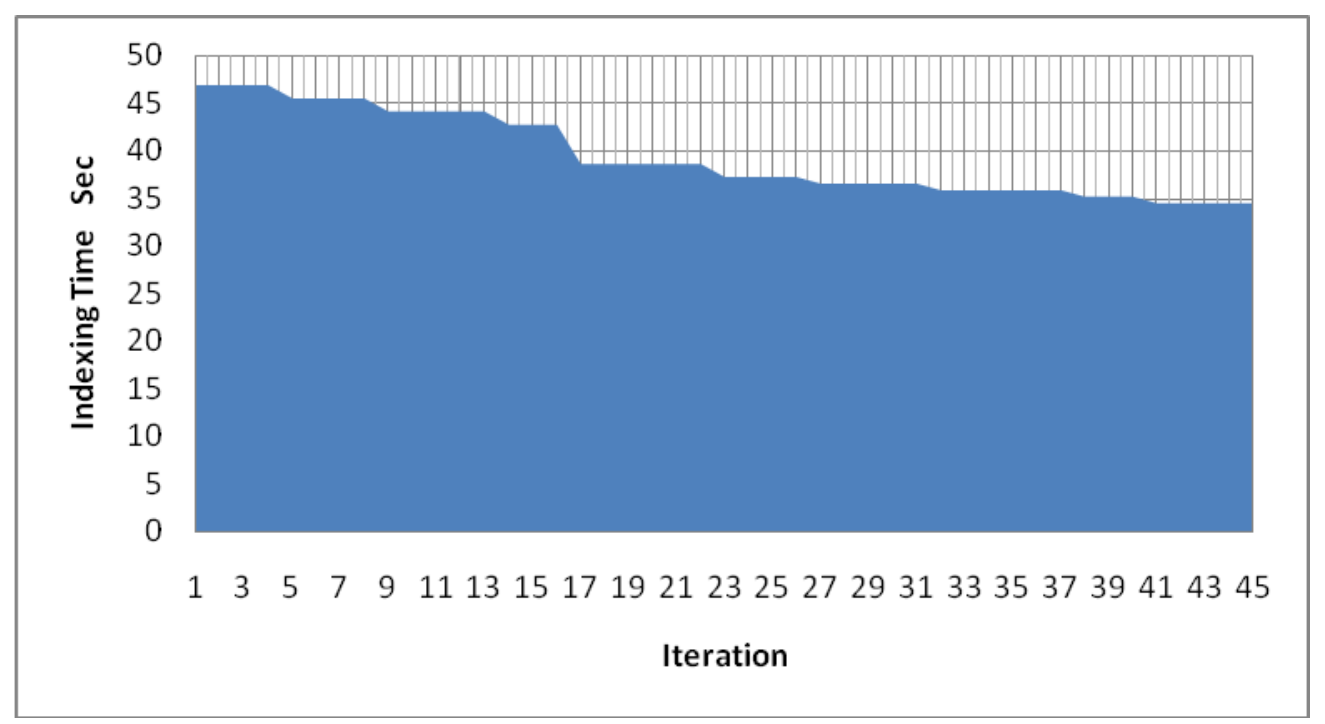

Figure 5. Solutions convergences

\subsection{Case Study 4:}

In this case 30 operations with 8 tools were used no additional duplication of tools from Adil Baykasoglu a \& Türkay Dereli(2007). The tooling capacity of ATC is 12 . The tool requirement of each operation is shown in Table 8 .

Table 8. Machining Operations and corresponding Tools

\begin{tabular}{|c|c|}
\hline Operation No & O1 O2 O3 O4 O5 O6 O7 O8 O9 O10 O11 O12 O13 O14 O15 O16 O17 \\
\hline Tools Assigned & 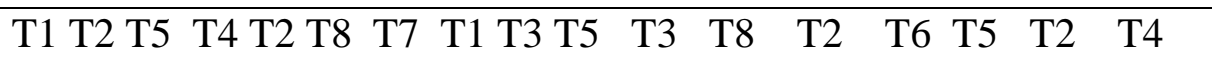 \\
\hline Operation No & O18 O19 O20 O21 O22 O23 O24 O25 O26 O27 O28 O29 O30 \\
\hline Tools Assigned & $\begin{array}{lllllllllllll}\text { T1 } & \text { T4 } & \text { T3 } & \text { T2 } & \text { T3 } & \text { T6 } & \text { T7 } & \text { T8 } & \text { T4 } & \text { T5 } & \text { T8 } & \text { T4 } & \text { T8 }\end{array}$ \\
\hline
\end{tabular}




\subsection{Case Study 5:}

In this case 45 operations with 15 tools were used no additional duplication of tools from Adil Baykasoglu a \& Türkay Dereli(2007). The tooling capacity of ATC is taken as 15. The detailed tool requirement is shown in Table 9.

Table 9. Machining Operations and corresponding Tools.

\begin{tabular}{|c|c|}
\hline Operation No & O1 O2 O3 O4 O5 O6 O7 O8 O9 O10 O11 O12 O13 O14 O15 O16 O17 \\
\hline Tools Assigned & 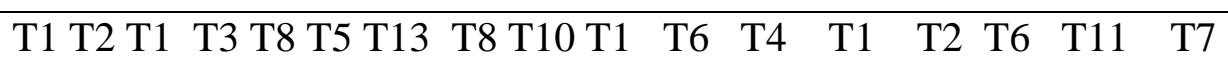 \\
\hline Operation No & O18 O19 O20 O21 O22 O23 O24 O25 O26 O27 O28 O29 O30 \\
\hline Tools Assigned & 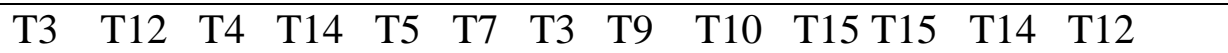 \\
\hline Operation No & O31 O32 O33 O34 O35 O36 O37 O38 O39 O40 O41 O42 \\
\hline Tools Assigned & 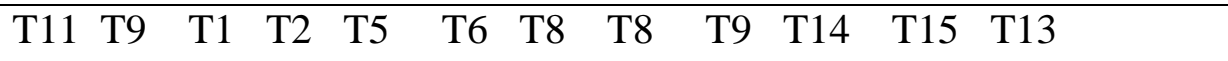 \\
\hline Operation No & $\mathrm{O} 43 \mathrm{O} 44 \mathrm{O} 45$ \\
\hline Tools Assigned & T15 T5 T11 \\
\hline
\end{tabular}

This case also considered Number of Tools are equal to Number of Turret which is compared to Number of Tools greater than number of turret (capacity 8). Which shows proposed method performs better than individual setup.

5. Result and discussion 
The Table 10 shows that summary of the results of all case studies. In most of the cases similar index time is obtained as given in the literature. In case 5, shows the superior performance than simulated annealing algorithm. The uniqueness of proposed algorithm gives many alternative sequences. The computational speed of the $\mathrm{CRO}$ algorithm is much faster than other algorithm reported in the literature, Combination and collaboration stage of the algorithm improves the solutions convergence of the algorithm by escaping from local minimum solutions.

Table 10. Summary of results

\begin{tabular}{|c|c|c|c|c|c|}
\hline $\begin{array}{l}\text { Bench Mark } \\
\text { problems }\end{array}$ & Authors & Method & $\begin{array}{l}\text { Optimal tool } \\
\text { position }\end{array}$ & $\begin{array}{l}\text { Total } \\
\text { Indexing } \\
\text { time } \\
\text { Seconds }\end{array}$ & $\begin{array}{l}\text { Number } \\
\text { of } \\
\text { optimal } \\
\text { sequences }\end{array}$ \\
\hline & \multirow[b]{2}{*}{$\begin{array}{l}\text { TürkayDerelia;_ } \\
\text { PI. HüseyinFiliz }\end{array}$} & $\begin{array}{l}\text { Genetic } \\
\text { Algorithm }\end{array}$ & 15427391086 & 8.97 & 1 \\
\hline $\begin{array}{l}\text { Problem } 1 \\
\text { (16 Operations } \\
\text { With } 10 \text { tools) } \\
\text { Indexing time } \\
=0.69 \mathrm{sec}\end{array}$ & & Proposed & $\begin{array}{l}16810973245 \\
16810937245 \\
15429371086 \\
16810739245 \\
16810793245 \\
15423971086 \\
15427391086 \\
15427931086\end{array}$ & 8.97 & many \\
\hline
\end{tabular}




\begin{tabular}{|c|c|c|c|c|c|}
\hline & & & 15429731086 & & \\
\hline & 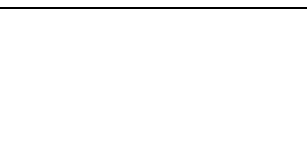 & $\begin{array}{l}\text { Scatter } \\
\text { Search }\end{array}$ & 987561243 & 10.35 & 1 \\
\hline $\begin{array}{l}\text { Problem } 2 \\
\text { ( } 17 \text { operations } \\
9 \text { tools) } \\
\text { Indexing } \\
\text { Time }=0.69 \mathrm{sec}\end{array}$ & $\begin{array}{l}\text { Alluru Gopala } \\
\text { Krishna . K. } \\
\text { Mallikarjuna Rao }\end{array}$ & Proposed & $\begin{array}{l}175689342 \\
123489342 \\
124398657 \\
123498756 \\
165789432 \\
175689342 \\
124398756 \\
124398657\end{array}$ & 10.35 & many \\
\hline \multirow[b]{2}{*}{$\begin{array}{l}\text { Problem } 3 \\
\text { ( } 27 \text { operations } \\
\text { with } 14 \text { tools) } \\
\text { Indexing Time } \\
=0.69 \mathrm{Sec}\end{array}$} & $\begin{array}{l}\text { Alluru Gopala } \\
\text { Krishna . K. } \\
\text { Mallikarjuna Rao }\end{array}$ & $\begin{array}{l}\text { Ant } \\
\text { colony } \\
\text { algorithm }\end{array}$ & $\begin{array}{l}123414 \quad 16710 \\
511121389\end{array}$ & 34.5 & 1 \\
\hline & & Proposed & $\begin{array}{l}171165101312 \\
1498432 \\
171365121110 \\
1498432 \\
19812136511 \\
10714234 \\
123414 \quad 16710 \\
511121389\end{array}$ & 34.5 & Many \\
\hline
\end{tabular}




\begin{tabular}{|c|c|c|c|c|c|}
\hline $\begin{array}{l}\text { Problem } 4 \\
\text { ( } 30 \text { operations } \\
\text { with } 8 \text { tools) }\end{array}$ & $\begin{array}{l}\text { Adil Baykasoglu } \\
\text { Türkay Dereli }\end{array}$ & $\begin{array}{l}\text { Simulated } \\
\text { annealing } \\
\text { algorithm }\end{array}$ & $\begin{array}{l}\text { With duplication of } \\
\text { each tools } 2 \text { times } \\
\text { maximum restricted } \\
12 \text { tools }\end{array}$ & 24 & 1 \\
\hline $\begin{array}{l}\text { Indexing time } \\
=0.69 \mathrm{sec}\end{array}$ & & proposed & $\begin{array}{l}\text { No duplication of } \\
\text { tools } \\
17635248 \\
18425367\end{array}$ & 26.5 & 2 \\
\hline $\begin{array}{l}\text { Problem } 5 \\
\text { ( } 45 \text { operations } \\
\text { with } 15 \text { tools) } \\
\text { Indexing time } \\
=0.50 \mathrm{sec}\end{array}$ & $\begin{array}{l}\text { Adil Baykasoglu } \\
\text { Türkay Dereli }\end{array}$ & $\begin{array}{l}\text { Simulated } \\
\text { annealing } \\
\text { algorithm }\end{array}$ & $\begin{array}{l}\text { Tools }>\text { Turret } \\
\text { Capacity }-8 \text { Nos } \\
5 \text { Setup change } \\
(10 \mathrm{sec} X 5=50 \mathrm{sec})\end{array}$ & $\begin{array}{c}16 \\
+50=66\end{array}$ & 1 \\
\hline
\end{tabular}

Conclusion

This research focus towards the optimization of ATC tool indexing time in CNC machine by new novel shortest path CRO algorithm. The computational study shows the obtained results 
are similar as in the literature and reach the globally optimum solutions in all of the case studies along with many alternative sequences obtained which is more useful for processing multiple job processed in different machines. In present industrial revolutions saving every seconds in the manufacturing industries which increases the production rate and energy computation. This developed algorithm can be used as standalone software package for solving any industrial problem with $\mathrm{N}$ number of tools with $\mathrm{M}$ number of operations. Further research is required to address the tool duplications which further reduces the indexing time by keeping two or more copies of tool in a indexing turret or magazine, but it further increase the complexity searching domain.

References

1. Krishna,A.G., Mallikarjuna Rao, M. 2006. Optimal allocation of index positions on tool magazines using an ant colony algorithm, International Journal of Advanced Manufacturing Technology, 30: 717-72.

2. Baykaso glu,A., Dereli,T. 2004. Heuristic optimization system for the determination of index positions on CNC magazines with the consideration of cutting tool duplications, International Journal Production Research, 42(7):1281-1303.

3. Dereli, T., Baykasoglu, A., Gindy, N., Filiz, I. 1998.Determination of optimal turretindex positions of cutting tools by using genetic algorithms. In: Proceedings of the second international symposium on intelligent manufacturing systems, 6-7.

4. Dereli,T., Filiz, I.H., 2000. Allocating optimal index positions on tool magazines using genetic algorithms. Robot Autonomous Systems, 33(2):155- 167. 
5. Ghosh, D. 2016a. A new genetic algorithm for the tool indexing problem. Tech. rep., Indian Institute of Management Ahmedabad, Research and Publication Department

6. Ghosh, D. 2016b. Allocating tools to index positions in tool magazines using tabu search. Tech. rep., Indian Institute of Management Ahmedabad, Research and Publication Department.

7. Ghosh, D.2016c. Comparing genetic algorithm crossover and mutation operators for the indexing problem. Tech. rep., Indian Institute of Management Ahmedabad, Research and Publication Department.

8. Ghosh, D. 2016d. Exploring Lin Kernighan neighborhoods for the indexing problem. Tech. rep., Indian Institute of Management Ahmedabad, Research and Publication Department.

9. Ghosh, D. 2016e. Incorporating gender and age in genetic algorithms to solve the indexing problem. Tech. rep., Indian Institute of Management Ahmedabad, Research and Publication Department.

10. Ghosh,D.2016f. Speeding up neighborhood search for the tool indexing problem. Tech. rep., Indian Institute of Management Ahmedabad, Research and Publication Department.

11. Velmurugan, M. and Victor Raj. M. 2013. Optimal Allocation of Index Positions on Tool Magazines Using Particle Swarm Optimization Algorithm. International Journal of Artificial Intelligence and mechatronics. 5-8.

12. Wilson, J.M. 1987, Formulation and Solution of a Set of Sequencing Problems for Flexible Manufacturing Systems. Proceedings of the Institute of Mechanical Engineering, 201: $247-249$. 